\title{
Vietnamese Women Marrying Korean Men and Societal Impacts. (Case studies in Dai Hop commune, Kien Thuy district - Hai Phong city)
}

\author{
Assoc. Prof. Ph.D. Hoang Ba Thinh \\ Director of Center for Gender, Population, Environment and Social Affairs, \\ Head of Department of Gender and Family - University of Social Sciences and Humanities, \\ Hanoi - Vietnam, Email: thinhhb@vnu.edu.vn
}

\section{Doi:10.5901/ajis.2013.v2n8p782}

\section{Abstract}

In the last decade, in Vietnam, there have been some research studies on marriages with foreigners, yet they mainly focused on Vietnam women getting married to Taiwanese men. There have been few research studies on Vietnam women marrying Korean men. Therefore, it is hoped that this research study will contribute to research on marriages with foreigners. In particular, its approach is from the multi-culture in marriage and international migration, and cultural factors that promote and hinder the process of Vietnam - Korean marriages. This research study was conducted in August 2009, and afterward we came back to conduct in-depth interviews with some Vietnamese women who get married to Korean men in September 2010. Besides using the method of literature review, this study combines both qualitative and quantitative methods. Through this research, the paper would like to find the societal impact of international marriages, in particular Vietnamese - Korean mariages to Vietnam.

\section{Introduction}

In the last decade, in Vietnam, there have been some research studies on marriages with foreigners, yet they mainly focused on Vietnam women getting married to Taiwanese men. There have been few research studies on Vietnam women marrying Korean men. Therefore, it is hoped that this research study will contribute to research on marriages with foreigners. In particular, its approach is from the multi-culture in marriage and international migration, and cultural factors that promote and hinder the process of Vietnam - Korean marriages.

This research study was conducted in August 2009, and afterward we came back to conduct in-depth interviews with some Vietnamese women who get married to Korean men in September 2010. The survey site is Dai Hop commune, Kien Thuy district- Hai Phong City (North Vietnam).

Besides using the method of literature review, this study combines both qualitative and quantitative methods. The sample is 150 parents of families in Dai Hop commune, Kien Thuy district, Hai Phong City whose daughters have got married to Korean men, and 15 in-depth inverviews (including parents, village and commune leaders, local people, women who got married to Korean men waiting for exit, Vietnamese women who married to Korean men on their visits to their families in Vietnam). We use simple sampling, based on the list of families whose daughters have got married to Korean men.

At the time of our survey in August 2009, Dai Hop commune had more than 721 women who had got married to foreigners including 188 women getting married to Korean men. In the sample of our survey using questionnaires, $82 \%$ households, each has a daughter getting married to a Korean man, 15.3\% households, each has two daughters getting married to Korean men and $1.3 \%$ households, each has 3 daughters getting married to Korean and Taiwanese men, $1.4 \%$ households each has 4 women getting married to Korean and Taiwanese men.

\section{Outline of Vietnamese women marrying Korean men}

\subsection{About Vietnam women marrying foreigners}

As of 2010 there were 294.280 cases of Vietnamese citizens married to foreigners or Vietnam people residing abroad, in over 50 countries and different regions (Ministry of Justice, 2011). Of which more than $80 \%$ of Vietnamese women married to foreigners or Vietnamese people settling in foreign countries, only about $20 \%$ of Vietnamese men married to 
foreign women.

Marriage and family relations involving foreign elements, including Vietnamese women married to foreign men since 1990s. Countries and territories with a large number of citizens marring Vietnamese people are Taiwan, South Korea, the Federal Republic of Germany, USA, Canada, France, Australia, Sweden, China... The rapid development of the marriage and family involving foreign elements mentioned above is an inevitable result of the development, of deeper integration in the areas of politics, economy, culture, society between Vietnam and other countries. In the early years of the twenty-first century, Vietnamese women marrying Taiwan, South Korea men were mainly in Can Tho, Dong Thap, An Giang, Tay Ninh, Soc Trang, Vinh Long...provinces. In recent years, there are some northern provinces of Vietnam such as Hai Duong, Hung Yen, Quang Ninh and Hai Phong having women marring foreigners.

\subsection{Situation of Vietnamese women marrying Korean men}

The number of marriage migrants increased to 210,000 from 150,000 in 2008, most of them from Asian countries such as China and Vietnam. The number of members from multicultural families created from international marriages reached 550,000 in 2011, up from 340,000 in 2008. The government expects to see the number of people to reach 1 million by 2020. (Cho Chung-un, 2013b)

Research shows an increasing numbers of Vietnamese women to get married and live in Korea. In 2000, only 95 cases of Vietnamese women married to Korean men, but by 2005 this figure increased by 61,3 times. Vietnam ranks the second with the number of bride in Korea (Kim, 2007). According to a 2012 Ministry of Gender Equality and Family report, around 266,547 multicultural families in Korea, in which national with Vietnam is $18.3 \%$, about 48,000 families. According to the Ministry of Justice, the number of marriage immigrants stood at about 145,000 at the end of 2011. Of the total, about 25.8 percent were women from Vietnam.(Choi He-suk, 2013), there have been more than 36,000 Vietnamese brides living in Korea. Marriages between Vietnamese women and Korean men second only to Chinese brides. In Hai Duong province (far from Hanoi capital about $50 \mathrm{~km}$ ), from 2006 to June 2009, there were 1,885 women marrying foreigners (Table 1)

Table 1. Vietnamese women marrying foreigners in Hai Duong province (unit: number people)

\begin{tabular}{|c|c|c|c|c|c|}
\hline Country & 2006 & 2007 & 2008 & $\ln 30 / 6 / 2009$ & Tota \\
\hline Taiwan & 102 & 134 & 116 & 65 & 417 \\
\hline Korea & 190 & 432 & 394 & 169 & 1194 \\
\hline China & 4 & 10 & 6 & 2 & 22 \\
\hline Australia & 6 & 14 & 5 & 4 & 29 \\
\hline US & 5 & 6 & 3 & 3 & 17 \\
\hline UK, Franch, German & 55 & 53 & 39 & 12 & 159 \\
\hline Others & 16 & 15 & 14 & 11 & 56 \\
\hline Total & 378 & 664 & 577 & 266 & 1884 \\
\hline
\end{tabular}

Source: Hai Duong Department of Culture - Sports - Tourism 2009.

Table 1 shows that, during the period from 2006 to mid 2009, Hai Duong province had 1884 women marrying foreigners, most of which were with Korean men, 1194 people (63.4 \%). In Ho Chi Minh City, from 2007 to 2011, 23244 cases of marriages involving foreign elements, including: 20,127 (86.6 \%) Vietnamese women marrying foreign people and 3,117 $(13.4 \%)$ cases of Vietnamese men with foreign elements. Marriage percentage of Vietnamese women with foreign elements is 6.4 times more than that of men. Among 20,127 Vietnamese women marrying foreigners, there are 7,391 marriages with U.S. citizens (31,8\%), 3,045 marriages with Korea $(13,1 \%), 2,068$ marriages with Canada $(8,9 \%), 1,883$ marriages with Australia (8,1\%), 1,650 marriages with France $(7,1 \%)$. Specially, in 2010, the number of marriages with Korea increased very fast. There were 365 marriages with Korean people but in 2010, the number was 996, increasing by 272\% (Ho Chi Minh Justice Department, 2012).

At the time of our survey in August 2009, Dai Hop commune had more than 721 women who had got married to foreigners including 188 women getting married to Korean men. In the sample of our survey using questionnaires, $82 \%$ households, each has a daughter getting married to a Korean man, 15.3\% households, each has two daughters getting married to Korean men and 1.3\% households, each has 3 daughters getting married to Korean and Taiwanese men, $1.4 \%$ households each has 4 women getting married to Korean and Taiwanese men (table 2). 
Table 2. Women in Dai Hop commune marrying foreign men, 1997-2009 (unit: number people)

\begin{tabular}{|l|l|l|l|l|}
\hline Year & Taiwan & Korea & Other & Total \\
\hline 1997 & 5 & 0 & 0 & 5 \\
\hline 1998 & 1 & 0 & 0 & 1 \\
\hline 1999 & 12 & 0 & 2 & 14 \\
\hline 2000 & 6 & 0 & 0 & 6 \\
\hline 2001 & 45 & 0 & 2 & 47 \\
\hline 2002 & 23 & 0 & 2 & 25 \\
\hline 2003 & 40 & 3 & 5 & 48 \\
\hline 2004 & 31 & 16 & 7 & 54 \\
\hline 2005 & 159 & 9 & 4 & 172 \\
\hline 2006 & 82 & 12 & 7 & 101 \\
\hline 2007 & 31 & 14 & 3 & 48 \\
\hline 2008 & 28 & 81 & 4 & 112 \\
\hline 2009 (in August 20 2009) & 24 & 53 & 10 & 87 \\
\hline Total & 487 & 188 & 46 & 721 \\
\hline
\end{tabular}

Source: Thinh, 2009.

According to statistics of Dai Hop commune People's Committee, women from Dai Hop commune started to marry foreign men in 1997, but this became a social issue since 2003, with two trends: getting married to Taiwanese men and Korean men. The number of women marrying Taiwanese men is highest with 487 cases (or $67.54 \%$ of total number of women marrying foreign men), next comes women marrying Korean men, with 188 cases (26.07\%), and the remaining 46 women marrying men from other nationalities (6.38\%). If consideration is made from 2003 - when Dai Hop women started to marry Korean men until August 2009, women marrying Korean men account for $30.2 \%$ of the total number of women in Dai Hop commune marrying foreigners. But since 2007, the number of women marrying Taiwanese men tends to decline while the number of women marrying Korean men tends to increase. In the last two years, the number of women marrying Korean men is 2.85 times higher than those marrying Taiwanese men (in 2008) and the figure was 2.36 times (in August 2009).

\section{Impacts of women married to Korean men on Vietnamese society}

\subsection{Economic and social impacts}

One of the motivations leading to Vietnamese women marrying foreign men in general and Korean men in particular is the economic factor. As discussed earlier, many young women want to have a better lives not only for themselves but also for their parents and family back in Vietnam, by earning money to remit to their families. Our survey shows that $53 \%$ parents having daughters getting married to Korean men say their children have remitted money to their family. The level of remittance is as follows: $8 \%$ regularly; $75.3 \%$ from time to time, and $17 \%$ rarely remit money to their families. Thanks to their remittance, many families in Dai Hop commune have improved their lives (repair of houses, purchase of household furniture and appliances), and some can build big, solid and beautiful houses thanks to the remittance from their daughters. These spacious and beautiful houses are called by the locals "Western Streets", or "Overseas Villages". They have also made some contributions to the local community:

"Whenever the village and commune need financial contributions, families whose daughters have got married to foreigners give a bigger amount of money than us. For example, if my family contributes VND 50,000, they will donate VND 500,000 to VND 1 million, sometimes several millions Dongs. They have also made a lot of contributions to the building of the family ancestral worship shrines".

It is this economic change that influences many parents and their daughters. It seems there is an implicit view that after finishing their schools, their girls will follow their elder sisters to get married to Korean men. As put it by a leader of Dai Hop commune "Now many families have an intention to marry their girls to foreigners that is why they allow them not to do anything, just to study the Korean language and wander around. This is the reason leading to their being lazy, not doing anything and are determined to marry foreign men" (Male, Chair of the commune)

Due to the fact that some Vietnamese-Korean marriages are made through match makers, who organize meetings for Korean men to select Vietnamese girls. This leads to a pressing public opinion in the community, offending the dignity of 
Vietnamese women and affecting social order and security.

\subsection{Impacts on human resources}

First of all, the localities having many young women marrying foreigners lose a source of young labor force. This is an important labor force as most of them are between 18 and 30 years of age and are educated. This young labor force is much needed for not only local but also national development because so far tens of thousands of Vietnamese young women have got married to foreign men. The "migration" through this type of international marriages not only causes a loss in young labor force but also creates gender imbalance in the country's population structure, particularly among young people. This makes the local marriage market difficult as discussed in section 5.4 below.

\subsection{Change of conception on the values of boys and girls.}

Vietnam is a nation influenced by the ideology of men preference. The conception that sons worship their ancestors has highly valued boys than girls, thus leading to the gender imbalance in childbirths in Vietnam. According to the results of the General Census on Population and Housing in 2009, the sex ratio at birth imbalance in Vietnam was 110 boys/100 girls. In some places, this sex ratio at birth imbalance is more serious. For example, the data processed on a sample of $3 \%$ of the results of the General Census on Population and Housing in 2009 show that the sex ratio at birth imbalance in some provinces and cities is very high. Some examples are: Hai Duong, Hung Yen: 120; Bac Giang:115.(Thinh, 2009; Central Steering Committee on Population and Housing General Census, 2010)

In the context of international marriages, in Dai Hop commune there is another perception: the idea of boy preference does not have a strong impact as in the past, if not to say there is a "change" in the values as people now value girls more. This is because, their girls, after marrying foreign men, help change their parent family's life while, if they have many boys, it is difficult to marry them in the village:

"I think today people in the village prefer to have girls so as to marry them to foreign men. Those who have many boys are considered by the locals not be wise in childbirths. That is true. People still want boys, but not many. Having many boys as in my case, I am worried" (Female, age 52, grade 7/10)

\subsection{Impacts on domestic marriage market}

For several years now, the issue of marriage of young men in Dai Hop commune has become more difficult than in the past. There are many reasons for this, but the most important one is that most of the girls here wish to marry foreign men. As analyzed in the previous section from 1997 to August 2009, the number of young women in Dai Hop commune marrying foreign men rose to 721 . This means in the same period, 721 young men in Dai Hop village who reach marriage age found it hard to marry young women in their commune. Thus, at the age of marriage, young men who fail to marry young women in their commune have to seek for girls from other places (see table 3).

Table 3: Situation of marriage of Dai Hop men by territorial areas, 2007-2009 (unit: number people)

\begin{tabular}{|l|l|l|l|l|l|}
\hline Year & In Dai Hop & Other communes & Other districts & Other provinces & Total \\
\hline 2007 & 32 & 30 & 24 & 14 & 100 \\
\hline 2008 & 43 & 23 & 23 & 28 & 117 \\
\hline $2009(20 / 8 / 2009)$ & 12 & 14 & 21 & 13 & 60 \\
\hline Total & 87 & 67 & 68 & 55 & 277 \\
\hline
\end{tabular}

Source: The author totals up and process data on the basis of marriage registration books of Dai Hop commune

Table 3 shows the reality of Dai Hop men getting married to women from other communes, in which only about $32 \%$ to $50 \%$ of young men can marry women in their commune (in 2007) (in 2008) and 20\% (in the first 8 months of 2009). From 2007 to August 2009, of the 277 men registered their marriages, only $31.4 \%$ got married to women in the commune, $27.7 \%$ got married to women in other communes; $24.5 \%$ in other districts and town and $19.8 \%$ in other provinces. So, since 2007 about 70\% men in Dai Hop commune, for different reasons, have got married to women outside their commune. Statistics of the first 8 months of 2009 show that of the 105 cases certified for marriages, only 14 cases $(13.3 \%)$ got married in the country. 
For men who got married to women in other communes in Kien Thuy district, statistics of marriage registration show that most of them got married to women in neighboring communes such as Tu Son, Doan Xa and Ngu Phuc. Cases of marriages to women in other districts concentrate in the districts of An Lao, Thuy Nguyen, Vinh Bao, and Do Son and An Duong Precincts (Hai Phong City).

Meanwhile, cases of men getting married to women in other provinces are very diverse ranging from the northern provinces of Lao Cai, Tuyen Quang, Lang Son, Phu Tho, Bac Kan to the Red River Delta provinces such as Bac Giang, Hai Duong, Nam Dinh, Thai Binh, Hung Yen, former Ha Tay to the central provinces of Thanh Hoa, Nghe An and Quang Nam.

When the local marriage market becomes more difficult with rare young women in the marriage age, men have to seek for their better half in other places. This is an inevitable rule in marriage and family, particularly in Vietnamese culture, especially in rural areas where people are not used to lead an unmarried life. Looking at the context of the marriage market in Dai Hop commune, there is no exception that the factors such as migration and integration in economic developments contribute to promoting marriages outside their commune. However, it is also noted that although Dai Hop is the most economically developed commune in Kien Thuy district, there are no factories or enterprises located in the commune and there are neither hotels nor restaurants. Thus there are no migrant workers from other parts to Dai Hop commune therefore, at the marriage age men have to seek their love partners from neighboring communes or in other districts and even other provinces. Our statistics show that from 2007 to August 2009, men in Dai Hop commune got married to women from 22 provinces and cities from the central province of Quang Nam to the northern provinces of Lao Cai, Tuyen Quang, and Lang Son. This figure represents $34.92 \%$ of provinces and cities in the country. It is known that in the previous years, some men even got married to women from southern provinces, thus the number of provinces and cities having women marrying men in Dai Hop commune is certainly more.

To confirm whether the relation is strong or weak between the trends of women marrying foreign men and men marrying women outside Dai Hop commune, it is needed to have further research. However, from initial findings and based on statistics and in-depth interviews, we can point to this relationship.

Table 4: Comparison of women marrying foreign men and men marrying women outside the commune in Dai Hop, 20072009 (unit: number people)

\begin{tabular}{|l|l|l|l|l|}
\hline Women marrying foreign & 2007 & 2008 & 2009 (8 months) & Total \\
\hline $\begin{array}{l}\text { Men marrying women outside the } \\
\text { commune }\end{array}$ & 48 & 112 & 87 & 247 \\
\hline $\begin{array}{l}\text { Men and Women marrying in Dai Hop } \\
\text { commune }\end{array}$ & 32 & 74 & 48 & 190 \\
\hline
\end{tabular}

Source: the author synthesized and processed of statistics Dai Hop commune

Table 4 shows that men who got married to women in Dai Hop commune only account for $45.7 \%$ compared to men marrying women outside their. In another words, every one man getting married to a women in the same commune, there are two men marrying women outside the commune. Meanwhile, the percentage of women marrying men in the commune is only $35.2 \%$ of that of women marrying foreign men. This means, the number of women marrying foreign men is three times higher than that of women marrying men in the commune. As an inevitable rule, when the number of young women in the commune declines, men have to seek for their wives from other places. Supposed there was no "wave" of women marrying foreign men, men in Dai Hop commune, at the age of marriage, would not tend to marry women out of their commune as many as it is seen. Obviously, young women in the marriage market in Dai Hop communes becomes more scarce, while most of the young women in the commune tend to seek a farther marriage market - overseas particularly the two countries of Taiwan and South Korea. This is not to include women marrying men from other parts of the country, thus making young women at marriage age in Dai become scarcer.

Commenting on the phenomenon of women marrying foreign men affecting the marriage opportunities of men, the Secretary of Dai Hop commune Party Organization says:

"The consequence is that the number of women at the age of marriage becomes scarce and thus men, at the age of marriage, have to get married to women outside the commune and some face difficulty in getting married. Along aside with gender imbalance in childbirths, it is certain that men will find it difficult to get married in the coming years". 
In this commune, families having sons, who are at the age of marriage, are very worried, as put it by a mother of a son who is more than 30 years of age:

"I've got three sons - 27, 25 and 23 years. None of them have got a lover yet. I really wish they would marry soon. I want them to get married to women from the village. They are all big built, tall and handsome. No one wants their sons to get married to women outside the village. Because it is less costly to marry local women. Other people who have got sons share my worry. Now if they want to marry, they have to travel to other communes or farther places to seek for their wives" (Female, 52 years, grade 7, fishing net making).

There are reasons for mothers to worry for their sons' marriages to women in the same commune, as put it by the Secretary of the commune Party Committee "Young women in Dai Hop say no to marriage to local men". This statement is famous in Kien Thuy district, Hai Phong City on the trend of marrying foreign men.

In the current context and in five to ten years to come, we forecast that the trend of young women in Dai Hop commune marrying foreign men will not reduce, thus, men in the commune will find it difficult to marry women from their commune. Due to the fact that the marriage market in the commune where "supply" of women is less than "demand", men here will have to find wives in other markets out of their commune, including in other provinces and cities.

\section{Discussion and Conclusion}

\subsection{Discussion}

That is the initial analysis on international Vietnamese - Korean marriages in Dai Hop, an outlying commune of Kien Thuy district, Hai Phong City, from the insiders' perspective. The most positive impacts of multi-cultural marriages (men marrying women outside their village and women marrying foreign men) are the increase of cultural exchanges and contribution to improving the quality of life (women who married foreign men remit money home for repairing and building houses and purchasing household furniture and appliances ..).

In our opinion, there must be further studies on the issues of marriages and Vietnamese- Korean families in this commune from the marriage market approach. However, the following are some of our discussions:

First, this study shows that marriages in the context of multi-cultures and international integration have taken place very obviously in a coastal commune. This multi-culture is not only expressed in domestic marriages (men marrying women from 22 provinces and cities) but also in international marriages (women from Dai Hop marrying men from 12 countries in Asia, Europe and North America, mostly Taiwan and Korea).

Second, the study contributes to confirming that marriages in the multi-cultural context are an inevitable trend and take place under the influences of many factors - economic, cultural and social - as well as the change in the traditional conception, values and norms on marriage and family. Prevention and prohibition of this trend is not feasible and voluntarist and violates the freedom of marriage.

Third, on theoretical approach on the marriage market and from the above case study it is noted that the impact of the scarcity of women in the Supply-Demand rule in the marriages of men. This can be considered a major challenge to young men, who want to seek their love partners in their village. This challenge will be more serious in the context of gender imbalance in childbirths in Vietnam. According to UN population specialists, "The absolute difference in the malefemale population structure in Vietnam in 2050 will be about 2.3 to 4.5 million persons" (UNFPA, 2009: 46).

Fourth, from the previous points, there will be a pressure to young men, particularly to parents who have sons in the marriage age, worrying for their sons' marriages. The scarcity of young women also lead to other social consequences, possibly leading to "competition" or "fight" for young women during the process of seeking for wives. This will possibly lead to fighting, violence, and crimes only because of women. In some rural areas in Vietnam there is a phenomenon of "blockading village young women", not allowing men from other parts to come to flirt their village young women (Thinh, 2008).

Fifth, the development of the marriage market in Dai Hop commune will create multi-cultural families. It is the combination of sub-cultures (domestic marriages, spouses from other parts) or the combination of different cultures (foreign-related marriages). With the "multi-cultural" families in this sense, it might lead to conflicts and domestic violence due to differences in sub-cultures between regions and ethnic groups (in case of domestic marriages) or language barriers, differences in customs and traditions and lifestyles (in case of foreign-related marriages). This will possibly increase the risk of disagreement and conflicts in the married life between spouses and between family members, leading to domestic violence, divorce, mixed children coming back to Vietnam and difficulties in the lives of children and in their 
schooling.

Sixth, the remittance of women who got married to foreign men to their families to purchase household appliances or repair and build houses creates "new streets" and "overseas villages". This improvement in the living conditions not only creates a social stratification in the living standards but also affects families who have got daughters. They all want to have foreign sons-in-law and they are "investing" in their girls (girls do not have to work, drop out of upper secondary schools, wear beautiful dresses, learn cooking and Korean or Taiwanese languages) so as to seek for foreign men as husbands. This leads to the trend in which young girls have a "dream to change their lives" through marriage with foreign men, even though they are not sure whether their married life will be good or bad.

Seventh, the "multi-cultural" marriage is also a problem for local authorities in social management. This is because of the movements, visits and temporary presence and temporary absence of members of families whose daughters have got married to foreign men and men marrying women outside the commune. This is even more difficult when people are not used to reporting their temporary absence and presence.

\subsection{Conclusion}

As discussed earlier, this study is the first one in Vietnam on international Vietnamese-Korean marriages from the insiders' perspectives. International Vietnamese-Korean marriages have both positive and negative impacts, but it is a normal phenomenon which is influenced by the process of globalization, particularly the process of Vietnam's integration into the world.

It is the internationally married families that serve as a bridge in strengthening the relationship between Vietnam and Korea. And the generation of their children - if they are given sufficient attention - will have good understanding of the cultures, languages of the two countries and will make a positive contribution to preserving and developing the Vietnamese- Korean friendship.

In our opinion, international marriages in general and Vietnamese-Korean marriages in particular should not be prevented or limited in number. But it is necessary to prevent illegal marriage match makers and serious sanctions should be applied against those who misuse international marriages to get benefits and deceive Vietnamese girls (and also Korean men) in marriage. Strong punishment should be given to those who misuse international marriages to traffic women and deceive Vietnamese girls into international prostitution.

What is important is that Vietnamese Government and South Korean Government should together with social organizations make further efforts in taking measures to support international Vietnamese-Korean marriages to make them more significant and truly valuable, and to have a really happy and sustainable married life. To this end, it is needed to educate citizens of the two countries, particularly those who want to have international Vietnamese-Korean marriages to learn about the cultures, laws, marriage and family and customs and traditions and religions of the two countries and have full information and understanding of their future spouses.

\section{References}

Cho Chung-un. 2013. Broken dreams for immigrant wives Korea urged to increase efforts to help marriage immigrants adapt; http://www.koreaherald.com/view.php? 2013-04-10

Choi He -suk. 2013. Little Psy' falls victim to racist attack; www.koreahearald.com/view.php 2013-05-02

Kim Young-won. 2013. Support centers help migrants adapt, integrate. www.koreaherald.com/view.php? 2013-05-08

Doo -Sub Kim. 2007. The Rise of Cross - border Marriage and Divorce in Contemporary Korea, Population and Society Vol. 3(1), Institute of Population and Aging Research, 2007, pp. 1-37

Thinh Hoang Ba.2010. Marriage characteristics and trends: A case study in Dai Hop commune. Journal of Family and Gender studies, Vol.20 No. 4/2010

Thinh Hoang Ba. 2009. Unbalance Sex ratio at birth in Vietnam. Journal of Figures \& Events, Vol. 11/2009

Thinh Hoang Ba. 2008. Vietnam - Korean Marriage: Socio - Cultural Aspects. Review of Social Sciences, Vol. 09 (121)/2008

Thinh Hoang Ba. 2006. The public Opinion of Marriage with Foreigners; Journal of Social Sciences and Humanities, Ho Chi Minh University, Vol. 36, 9/2006

Ministry of Justice. 2011. Report on the implementation of Instruction no 03/2005/CT-TTg released on 25/02/2005 by Prime Minister about the enforcement of governmental authority on marriage and family relationship with international factor

People's Committee of Dai Hop.2009. List of women marrying with foreigners, 1997- 8/ 2009

UNFPA. 2009. Recent change in the Sex ratio at birth in Viet Nam - A Review of Evidence; Hanoi, August 2009 
